\title{
Catalytic Effects of Ruthenocene Bimetallic Compounds Derived from Fused Aromatic Ring Ligands on the Main Oxidizing Agent for Solid Rocket Motor
}

\author{
Yuvaraja Dibdalli, ${ }^{a}$ José Gaete, ${ }^{b}$ Claudio Osorio-Gutierrez, ${ }^{b}$ Juan Luis Arroyo, ${ }^{c}$ \\ Angel Norambuena, ${ }^{c}$ Mungalimane K. Amshumali, ${ }^{a}$ Gabriel Abarca ${ }^{\circledR b}$ and \\ Cesar Morales-Verdejo ${ }^{\oplus *, b}$ \\ ${ }^{a}$ Department of Chemistry/Industrial Chemistry, Vijayanagara Sri Krishnadevaraya University, \\ Vinayakanagara, Cantonment, Ballari, 583105 Karnataka, India \\ ${ }^{b}$ Centro Integrativo de Biología y Química Aplicada (CIBQA), Universidad Bernardo OHiggins, \\ General Gana, 1702, Santiago, Chile \\ ${ }^{c}$ Laboratorio de Materiales Energéticos, Instituto de Investigaciones y Control del Ejército de Chile (IDIC), \\ Av. Pedro Montt, 2136, Santiago, Chile
}

\begin{abstract}
We report the catalytic effect of three ruthenocene bimetallic compounds derived from fused aromatic rings of general formula $\left[\{\mathrm{Cp} * \mathrm{Ru}\}_{2} \mathrm{~L}\right]$, with $\mathrm{Cp}^{*}$ : pentamethylcyclopentadiene and $\mathrm{L}=$ pentalene (1), 2,6-diethyl-4,8-dimethyl-s-indacene (2), and 2,7-diethyl-as-indacene (3), on the thermal decomposition of ammonium perchlorate (AP). The new compound $\mathbf{3}$ was characterized by a combination of multinuclear magnetic resonance (NMR) spectroscopy and elemental analysis. The differential scanning calorimetry (DSC) analysis of compound $\mathbf{3}$ shows a decrease in the decomposition temperature of AP to $347^{\circ} \mathrm{C}$, increases the energy release to $2048 \mathrm{~J} \mathrm{~g}^{-1}$ and, consequently, leads to the lowest activation energy $\left(42.9 \mathrm{~kJ} \mathrm{~mol}^{-1}\right)$. These results are comparable to the typically used metallocene (catocene: $347^{\circ} \mathrm{C}$ and $2472 \mathrm{~J} \mathrm{~g}^{-1}$ ), suggesting a suitable and competitive alternative to be used as a modifier for composite solid propellants.
\end{abstract}

Keywords: thermal decomposition, burning rate, catalysis

\section{Introduction}

Improving the combustion of ammonium perchlorate (AP), the most common oxidizer in the solid rocket propellant, is the key in energetic materials in the space race. ${ }^{1}$ Nevertheless, considering the limited loading of AP used for the development of rockets, it is imperative to increase its decomposition effectiveness further to produce a large amount of energy as far as possible and to decrease its combustion temperature for easy operation and control. ${ }^{1}$ Different types of burning rate (BR) catalysts such as nanoparticles,,$^{2-8}$ coordination complexes, ${ }^{9-11}$ and ferrocene derivatives ${ }^{12-17}$ have been studied to improve the decomposition efficiency of AP. Among them, ferrocenelike homobimetallic compounds have recently reached huge attention due to their microscopic homogeneity in the distribution with the binder agent (HTPB: hydroxyl-

*e-mail: cesar.morales@ubo.cl

Editor handled this article: Jaísa Fernandes Soares terminated polybutadiene) and the astonishing effects over the burning rates and pressure indexes of the propellants. ${ }^{12,16,18-21}$

Since the thermal degradation of AP has a close relationship with the combustion process of the composite solid propellant, the combustion effect of BR catalyst candidates on the combustion behavior of the composite solid propellants is usually assessed by its effect on the thermal degradation of AP. In this context, it has been reported that suitable BR catalysts give rise to a shift in the high-temperature decomposition (HTD) peak of AP to the left, accelerating AP decomposition as well as increasing the released heat of AP. ${ }^{15,22}$

Different BR catalysts have not been extensively explored ferrocene derivatives, except as published by our group employing heterobimetallic compounds..$^{20,23}$ About using ruthenium compounds for thermal AP decomposition, a few reports have been found, where Hayashi et al. ${ }^{24}$ and Wang et al. ${ }^{25}$ demonstrated that ruthenium nanoparticles could be a suitable system for ammonia decomposition $\mathrm{CO}_{\mathrm{x}}$-free hydrogen. 
Furthermore, metallocenes derived from fused delocalized polycyclic bridging ligands are frequently precursors of stable mixed-valence complexes due to a powerful electronic interaction through the spacer ligand. ${ }^{26-29}$ The synthetic path to achieve a whole series of homobimetallic systems derived from $s$-indacene $\mathrm{e}^{27,28,30}$ and $a s$-indacene ${ }^{17}$ has been accomplished by our group to understand the electronic properties permitting the intermetallic communication in the mixed-valence compounds. Here, we describe the catalytic activity of ruthenocene bimetallic complexes derived from $s$-indacene, pentalene, and as-indacene and compare with ferrocene $(\mathrm{Fc}), 2$,2-bis (ethylferrocenyl)propane (catocene: Cat) and their analogous iron complexes.

\section{Experimental}

\section{Reagents and characterization methods}

Ferrocene $(\mathrm{Fc})$ was purchased from Aldrich (Saint Louis, Missouri, United States of America). Analytical pure grade AP with a particle size of $200 \mu \mathrm{m}$ was purchased from SNPE Propulsion, Groupe SNPE (Toulouse, France). Reagent grade solvents (hexane, toluene, and tetrahydrofuran) were distilled under an atmosphere of nitrogen from sodium benzophenone (earlier distilled from $\mathrm{AlLiH}_{4}$ ). ${ }^{31}$ All handlings were carried out under a pure nitrogen atmosphere using a vacuum atmosphere dry box equipped with a Model HE 493 Dri-Train purifier (Hawthorne, California, United States of America) or with the use of a vacuum line by using standard Schlenk tube techniques.

Elemental analyses $(\mathrm{C}$ and $\mathrm{H})$ were made with a Fisons EA 1108 microanalyzer (Waltham, Massachusetts, United States of America). ${ }^{1} \mathrm{H}$ and ${ }^{13} \mathrm{C}$ nuclear magnetic resonance (NMR) spectra were recorded on Bruker AC-400 and Bruker AC-200P spectrometers (Billerica, Massachusetts, United States of America). Chemical shifts were reported in ppm relative to residual solvent signals and were assigned via 2D NMR homo- and heterocorrelational techniques.

Differential scanning calorimetry (DSC) analyses were performed on a 822e Mettler Toledo instrument (Columbus, Ohio, United States of America) at a heating rate of 2, 5 and $10{ }^{\circ} \mathrm{C} \mathrm{min}-1$ under nitrogen $\left(50 \mathrm{~mL} \mathrm{~min}^{-1}\right.$ flow $)$ in the range of $140-450{ }^{\circ} \mathrm{C}$, using $40 \mu \mathrm{L}$ aluminum pans with a pin on the bottom. The catalytic performance of the compounds derived from pentalene, $s$-indacene, and as-indacene for the thermal decomposition of AP was investigated by adding the catalysts to $\mathrm{AP}(20 \mathrm{~mm}$ size) in 1, 3, and $5 \mathrm{wt} \%$ (average sample mass $=2.430 \mathrm{mg}$ ).

The activation energy $\left(\mathrm{E}_{\mathrm{a}}\right)$ determination was carried out using the ASTM method e628..$^{32}$ The samples were heated from 140 to $450{ }^{\circ} \mathrm{C}$ with a heating rate of 2,5 and $10{ }^{\circ} \mathrm{C} \mathrm{min}{ }^{-1}$. Temperatures of reaction peak maxima were corrected for temperature scale nonlinearity. $\log _{10} \beta$ (heating rate, $\mathrm{K} \mathrm{min}^{-1}$ ) versus $1 / \mathrm{T}$ were plotted, where $\mathrm{T}$ is Kelvin's fixed maximum temperature. The calculation and construction of the least-squares "best fit" line through these points was performed. The slope of this "best fit" line was taken as the value for $d \log _{10} \beta / d(1 / T)$. The calculation of value for $\mathrm{E}_{\mathrm{a}}$ (activation energy) was determined according to the following equation.

$E_{a}=-2.19 R\left[d \log _{10} \beta / d(1 / T)\right]$

where $\mathrm{R}$ is the gas constant $\left(=8.314 \mathrm{~J} \mathrm{~mol}^{-1} \mathrm{~K}^{-1}\right)$.

The synthesis of the following complexes has been reported previously: $\left[\mathrm{Cp} * \mathrm{Ru}\left\{\mathrm{m}_{3}-\mathrm{Cl}\right\}\right]_{4},{ }^{33}\left[\{\mathrm{Cp} * \mathrm{Ru}\}_{2}\right.$-pen $]$ (1), ${ }^{26}$ pentamethylcyclopentadiene $\left(\mathrm{Cp}^{*}\right)$ and pen: pentalene [\{Cp*Ru $\}_{2}-s$-Ic'] $(2),{ }^{27} s$-Ic': 2,6-diethyl-4,8-dimethyl$s$-indacene, ${ }^{34}$ and $a s$-Ic': 2,7-diethyl-as-indacene. ${ }^{35}$

Synthesis of $\left[\left\{C p^{*} R u\right\}_{2}-a s-I c^{\prime}\right]$

An $n$-butyl-lithium solution $\left(2.0 \mathrm{~mol} \mathrm{~L}^{-1}\right.$ in cyclohexane, $0.37 \mathrm{~mL}, 0.73 \mathrm{mmol}$ ) is added drop by drop to a solution of $a s$-Ic' $\mathrm{H}_{2}(0.08 \mathrm{~g}, 0.37 \mathrm{mmol})$ in tetrahydrofuran $(25 \mathrm{~mL})$ at $-78^{\circ} \mathrm{C}$. The resulting solution is stirred for $2 \mathrm{~h}$ at room temperature. Subsequently, a solution of $\left[\mathrm{Cp} * \mathrm{Ru}\left\{\mathrm{m}_{3}-\mathrm{Cl}\right\}\right]_{4}$ $(0.20 \mathrm{~g}, 0.19 \mathrm{mmol})$ in tetrahydrofuran $(20 \mathrm{~mL})$ is slowly added to the mixture of the dilithiated compound $\mathrm{Li}_{2}$ (as-Ic') at $-78{ }^{\circ} \mathrm{C}$, and the suspension is vigorously stirred. The reaction mixture is heated to room temperature and stirred during the night. After removing the tetrahydrofuran, the resulting solid product is dissolved with toluene and filtered off to eliminate the insoluble LiCl. A dark-red stable to air powder-like solid is obtained. Yield: $0.10 \mathrm{~g}$ (50.2\%); anal. calcd for $\mathrm{C}_{36} \mathrm{H}_{46} \mathrm{Ru}_{2}$ (680.14): C, 63.60; $\mathrm{H}, 6.67$; found: $\mathrm{C}, 63.29 ; \mathrm{H}, 6.87$; ${ }^{1} \mathrm{H}$ NMR $(400 \mathrm{MHz}$, $\left.\mathrm{CDCl}_{3}\right) \delta 0.76\left(\mathrm{t}, 6 \mathrm{H}, \mathrm{C}\{H\}_{3}-\mathrm{CH}_{2}-\mathrm{C}_{(5,8,)}\right), 1.17$ (s, 30H, $\left.\mathrm{C}\{H\}_{3}\left(\mathrm{Cp}^{*}\right)\right), 2.41\left(\mathrm{q}, 4 \mathrm{H}, \mathrm{CH}_{3}-\mathrm{C}\{H\}_{2}-\mathrm{C}_{(5,8,}\right), 3.17$ (s, $\left.2 \mathrm{H}, \mathrm{C}_{(1,7)}\{H\}\right), 3.25\left(\mathrm{~s}, 2 \mathrm{H}, \mathrm{C}_{(4,6)}\{H\}\right), 7.02\left(\mathrm{~s}, 1 \mathrm{H}, \mathrm{C}_{(2)}\right.$ $\{H\}), 7.16\left(\mathrm{~s}, 1 \mathrm{H}, \mathrm{C}_{(3)}\{H\}\right) ;{ }^{13} \mathrm{C} \mathrm{NMR}\left(100 \mathrm{MHz}, \mathrm{CDCl}_{3}\right)$ $\delta 13.34\left(\{C\} \mathrm{H}_{3}\left(\mathrm{Cp}^{*}\right)\right), 14.12\left(\{C\} \mathrm{H}_{3}-\mathrm{CH}_{2}-\mathrm{C}_{(5,8)}\right)$, $22.70\left(\mathrm{CH}_{3}-\{C\} \mathrm{H}_{2}-\mathrm{C}_{(5,8)}\right), 59.53$ (see Scheme 1)

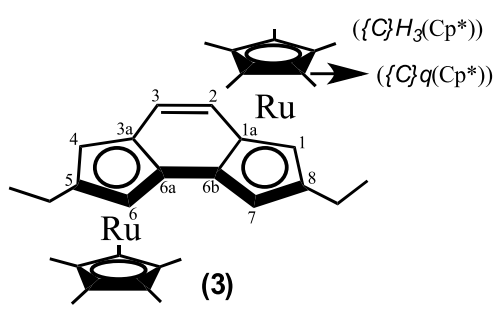

Scheme 1. Labeling scheme used for NMR assignation for complex 3 . 
$\left.C_{(1,4,6,7)}\right), 77.20\left(\{C\} \mathrm{q}\left(\mathrm{Cp}^{*}\right)\right), 122.99\left(C_{(5,8)}\right), 133.87\left(C_{(2,3)}\right)$, $144.33\left(C_{(1 \mathrm{a}, 3 \mathrm{a}, 6 \mathrm{a}, 6 \mathrm{~b})}\right)$.

\section{Results and Discussion}

\section{Synthesis and characterization}

Ferrocene-type compounds have been reported to be effective catalysts on the thermal decomposition of AP. ${ }^{12-14,16,17}$ These previous reports inspired us to test the activity of the ruthenocene-derived bimetallic compounds $\mathbf{1}, \mathbf{2}$, and $\mathbf{3}$ (Figure 1) as potential burning rate catalysts compared with ferrocene $(\mathrm{Fc})$, catocene (Cat), and their analogous iron compounds, and determine the existence of unusual effects when the two moieties are different from ferrocene on the thermal degradation of AP.

The homobimetallic complex derived from the asindacene ligand (3) was prepared using a previously reported route ${ }^{17,27}$ (Scheme 2). In the dianion formation, the dihydro-as-indacene was doubly deprotonated with two equivalents of $n$-butyllithium, as shown in Scheme 2 . Once the dianion was prepared, it can be coupled to the metallic fragment via salt elimination. With this procedure, our working group has successfully synthesized several homobimetallic complexes. ${ }^{17,26-28,30}$

The NMR spectroscopic studies of both nuclei were carried out compared to previous works found in the literature. ${ }^{17,35}{ }^{1} \mathrm{H}$ and ${ }^{13} \mathrm{C}$ NMR spectra show that the ruthenocene compound derived from as-indacene, (3), is produced as a sole isomer, i.e., the anti-configuration. Earlier studies ${ }^{36}$ have shown that the isomer ratio depends on a mixture of factors, including the ancillary ligand nature, steric hindrance, and symmetry of the bridging ligand. Ceccon et $_{\text {al }} .^{36}$ showed that incorporating different ancillary ligands with different sizes promotes the formation of syn or anti isomers. Small ligands (1,5-cyclooctadiene (COD) or norbornadiene (NBD)) prefer the syn isomer, and the large ligands (cyclopentadienyl) prefer anti conformation. In our case, we achieved the anti isomer due to the $\{\mathrm{Cp} * \mathrm{Ru}\}$ fragment imposing a steric hindrance to the entrance of the second organometallic fragment to the same side of the spacer as-indacene ligand, selectively favoring the anti isomer, explaining the formation of only one isomer as the final product.

A noteworthy feature in the ${ }^{1} \mathrm{H}$ NMR spectrum is the clean proton assignment corresponding to the coordinated five-membered ring of the as-indacene ligand at 3.17-3.25 ppm and pentamethylcyclopentadiene (Cp*) ligand at $1.17 \mathrm{ppm}$ (Figure 2).

The ${ }^{13} \mathrm{C}$ NMR spectrum of the compound 3 was assigned using 2D NMR tools. This spectrum presents remarkable features, corresponding to the signals at 13.34 and $14.12 \mathrm{ppm}$, consistent with $-\mathrm{CH}_{3}$ groups belonging to the bridging $a s$-indacene and $\mathrm{Cp}^{*}$ ligands. On the other hand, the signal at $77.20 \mathrm{ppm}$ equivalent to quaternary carbons belonging to $\mathrm{Cp}^{*}$ ancillary ligand appears between the residual solvent signals of the deuterated chloroform (Figure S1, Supplementary Information (SI) section), this signal is located in a region similar to the previously reported complexes derived from ruthenium. . $3,27^{27}$

\section{Catalytic effects on thermal decomposition of AP}

The catalytic behavior of the ruthenocene homobimetallic compounds on the thermal degradation of AP were explored by DSC measurements. The DSC curves of both AP and the mixture of AP with the label compound are shown in Figure 3 and Figures S2-S3 (SI section). The

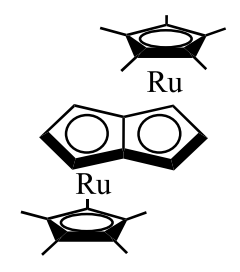

(1)

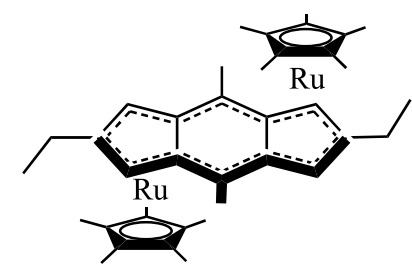

(2)

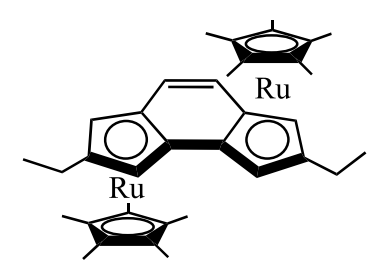

(3)

Figure 1. Ruthenocene homobimetallic $(\mathbf{1}, \mathbf{2}$, and $\mathbf{3})$ catalysts compared in this work.
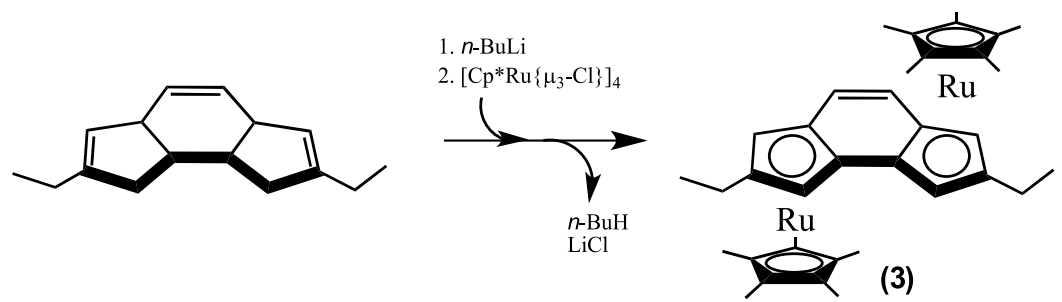

Scheme 2. Synthetic pathway of the homobimetallic complex [ $\{\mathrm{Cp} * \mathrm{Ru}\}_{2}-a s$-Ic'] (3). 


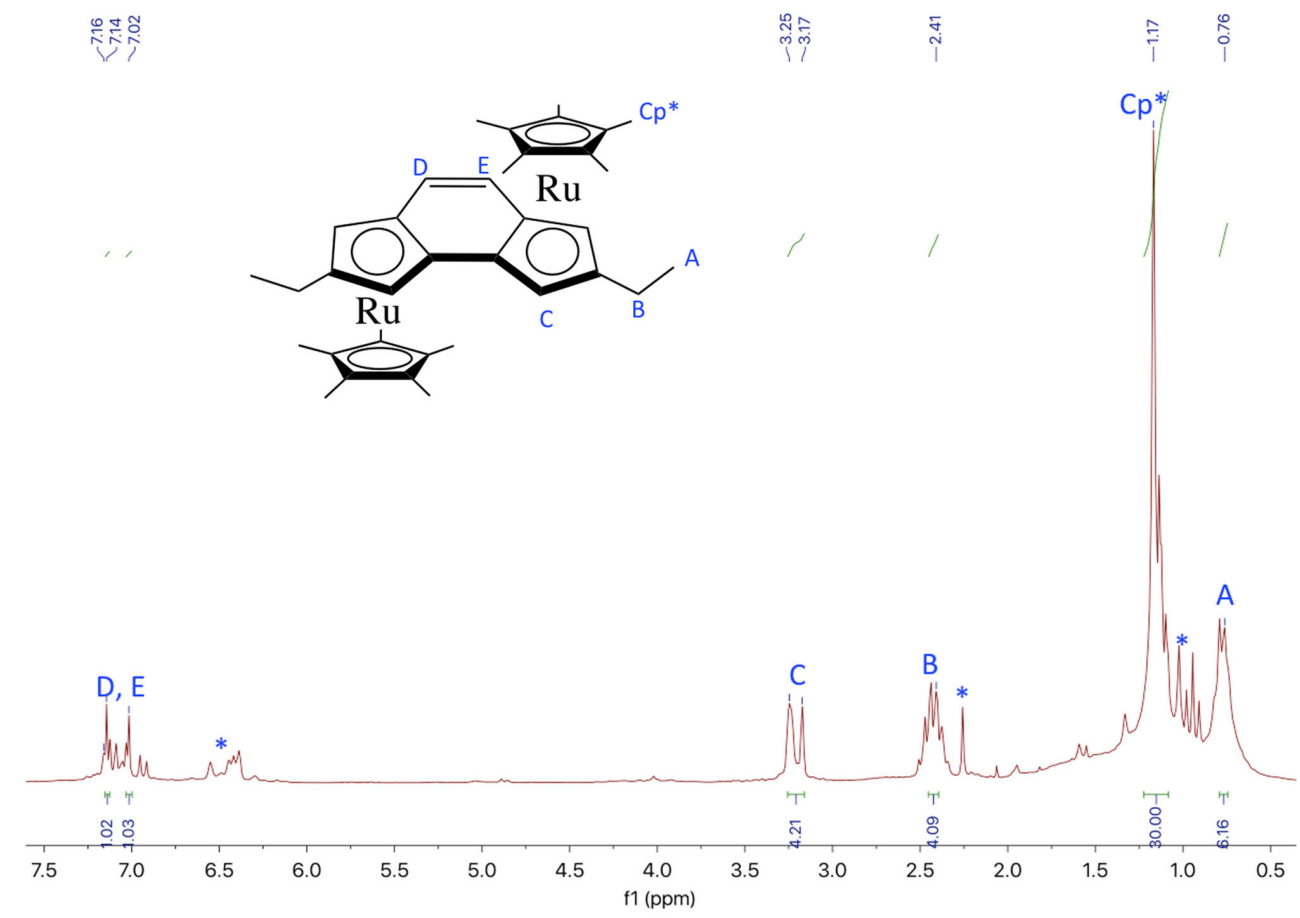

Figure 2. ${ }^{1} \mathrm{H}$ NMR $\left(400 \mathrm{MHz}, \mathrm{CDCl}_{3}\right)$ spectrum of $\left[\{\mathrm{Cp} * \mathrm{Ru}\}_{2}\right.$-as-Ic']. *Impurities from the free ligand.

mass percentages of ruthenocene-based BR catalysts used in AP were 1, 3 and 5 wt.\%.

In general, the performance of AP as the principal component of the composite solid propellant can be improved by changing its peak temperatures to the left and raising the heat released during thermal degradation with the addition of BR catalysts.

In the same way as ferrocene-based BR catalysts, the phase transition endothermic process of AP at $249{ }^{\circ} \mathrm{C}$ had practically no shift and exhibited a similar profile to different wt.\% of compounds $\mathbf{1}, \mathbf{2}$, and $\mathbf{3}$ as an additive, indicating that the catalysts have a minimal effect on the AP crystallographic transition temperature. On the other hand, the AP's high-temperature degradation (HTD) step (at $415^{\circ} \mathrm{C}$ ) was considerably affected by adding the catalysts derived from ruthenocene compounds.

After adding the compounds $\mathbf{1}$ and $\mathbf{2}$ at $1 \mathrm{wt} . \%$, the HTD increases, and the heat released decreases, acting as retarding agents (Figures S2-S3, SI section). At higher wt.\%, the catalytic effect of compounds $\mathbf{1}$ and $\mathbf{2}$ improve, lowering the decomposition temperature and increasing the heat released by the mixture. However, in compound $\mathbf{2}$, the maximum shift of the decomposition temperature at $5 \mathrm{wt} . \%$ is obtained at $412{ }^{\circ} \mathrm{C}$, with a heat release of $669 \mathrm{~J} \mathrm{~g}^{-1}$, not comparable with the other ruthenocenes here reported.

Generally, when the wt.\% of the catalytic species was increased from 1 to 5 , obtaining the best catalytic effects at $5 \mathrm{wt} . \%$, they were selected as the best amount of each compound to assess their catalytic effects. After adding

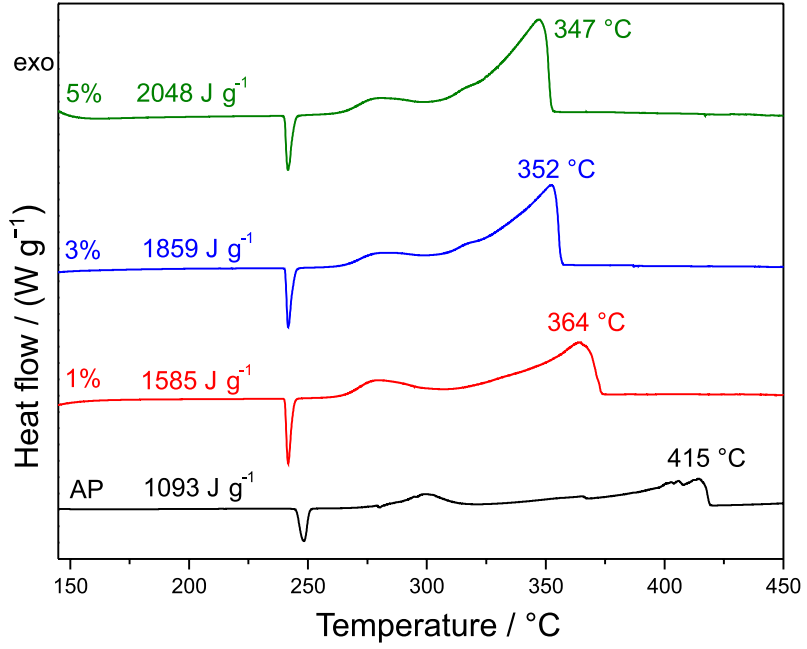

Figure 3. DSC curves of AP with different percentage (wt.\%) of compound 3.

$5 \%$ by weight of the additives (1), (2), and (3), the HTD decreased to 371,412 , and $347^{\circ} \mathrm{C}$, respectively, producing a left shift by 44,3 , and $68^{\circ} \mathrm{C}$ compared to pure AP, which implies the catalysts $\mathbf{1}$ and $\mathbf{3}$ have and an evident catalytic effect on the thermal degradation of AP.

Regarding compound $\mathbf{3}$, in comparison with $\mathbf{1}$ and $\mathbf{2}$, the exothermic step of AP is more critically influenced to the left. The heat released with complex $\mathbf{3}$ is higher than for all compounds reported here $\left(2048 \mathrm{~J} \mathrm{~g}^{-1}\right)$ but lower compared to catocene (see Table 1).

Moreover, notably, all the DSC curves exhibited an akin shape with two peaks in each DSC curve, suggesting an 
analogous degradation mechanism of the mixture systems to be expected (Figure 3 and Figures S2-S3, SI section).

The influence of the ruthenocene homobimetallic complexes on the catalytic thermal degradation of AP corresponds to an increase of the heat released, except for complex 2 with a relationship of 0.6 times. In the case of the mixtures, AP $+(\mathbf{3})$ provides 1.9 times over neat AP (Table 1), as mentioned above, close to the catocene (ratio 2.3).

On the other hand, if we compare the catalytic effects of their iron analog compounds, it is possible to observe the same tendency in the heat released between the $s$-indacene and $a s$-indacene derivatives, ${ }^{17}$ where the iron as-indacene compound, [ $\{\mathrm{Cp} * \mathrm{Fe}\}_{2}$-as-Ic'], showed higher heat release as in our case with the ruthenium analog, $\left[\{\mathrm{Cp} * \mathrm{Ru}\}_{2}\right.$-as-Ic']. Thus, although the heat released by complex $\mathbf{3}$ is higher than by the iron derivatives, the catalytic effects on the thermal decomposition of AP are lower in the ruthenium compounds reported here.

Table 1. Effect of the different additives on the thermal degradation of AP

\begin{tabular}{lcccc}
\hline Compound & $\begin{array}{c}\text { Mass / } \\
\text { wt.\% }\end{array}$ & $\begin{array}{c}\mathrm{HTD} \text { of } \\
\mathrm{AP} /{ }^{\circ} \mathrm{C}\end{array}$ & $\begin{array}{c}\text { Heat } \\
\text { released / } \\
\left(\mathrm{J} \mathrm{g}^{-1}\right)\end{array}$ & $\begin{array}{c}\text { Heat } \\
\text { released } \\
\text { ratio }^{\mathrm{a}}\end{array}$ \\
\hline $\mathrm{NH}_{4} \mathrm{ClO}_{4}(\mathrm{AP})$ & 5 & 410 & 1093 & 1 \\
$\mathrm{Fc}$ & 5 & 360 & 1313 & 1.2 \\
$\mathbf{1}$ & 5 & 371 & 1718 & 1.6 \\
$\mathbf{2}$ & 5 & 412 & 669 & 0.6 \\
$\mathbf{3}$ & 5 & 347 & 2048 & 1.9 \\
$\mathrm{Cat}^{37}$ & 5 & 346 & 2472 & 2.3 \\
$\mathrm{Fe}_{2} \mathrm{O}_{3}$ & 5 & 352 & 1839 & 1.7 \\
{$\left[\{\mathrm{Cp} * \mathrm{Fe}\}_{2} s \text {-Ic' }\right]^{17}$} & 5 & 321 & 1594 & 1.5 \\
{$\left[\{\mathrm{Cp} * \mathrm{Fe}\}_{2} a s \text {-Ic' }\right]^{17}$} & 5 & 320 & 1870 & 1.7 \\
\hline
\end{tabular}

atio between the heat released by the mixture and the heat released by pure AP. HTD: high-temperature decomposition; AP: ammonium perchlorate $\left(\mathrm{NH}_{4} \mathrm{ClO}_{4}\right) ; \mathrm{Fc}$ : ferrocene; Cat: catocene (2,2-bis (ethylferrocenyl) propane); Cp*: pentamethylcyclopentadiene; $s$-Ic': 2,6-diethyl4,8-dimethyls-indacene; as-Ic': 2,7-diethyl-as-indacene.

Lastly, the combinations "AP + ligands" are ineffective catalysts for the thermal degradation of ammonium perchlorate, compared to their respective "AP + ruthenocenes" analogs, essentially because the ligands do not produce an active enough catalytic species to ensure a well-performed burning process.

Furthermore, a study of the thermal decomposition kinetics of the mixtures of the ruthenocenes compounds with AP (5 wt.\%) was carried out using the ASTM method e628. ${ }^{32}$ The activation energy $\left(\mathrm{E}_{\mathrm{a}}\right)$ was also measured, as Table 2 shows. The samples were heated from $140{ }^{\circ} \mathrm{C}$ (rate 2, 5, $10{ }^{\circ} \mathrm{C} \min ^{-1}$ ), and the $\mathrm{E}_{\mathrm{a}}$ values were obtained in the range of 43-138 kJ mol ${ }^{-1}$ (Figure 4). Comparing the mixtures of ruthenocenes complexes with AP, the combination "AP $+(3)$ " has the lowest activation energy $\left(42.9 \mathrm{~kJ} \mathrm{~mol}^{-1}\right)$, indicating a low degree of thermal stability, accelerating the thermal decomposition of AP.

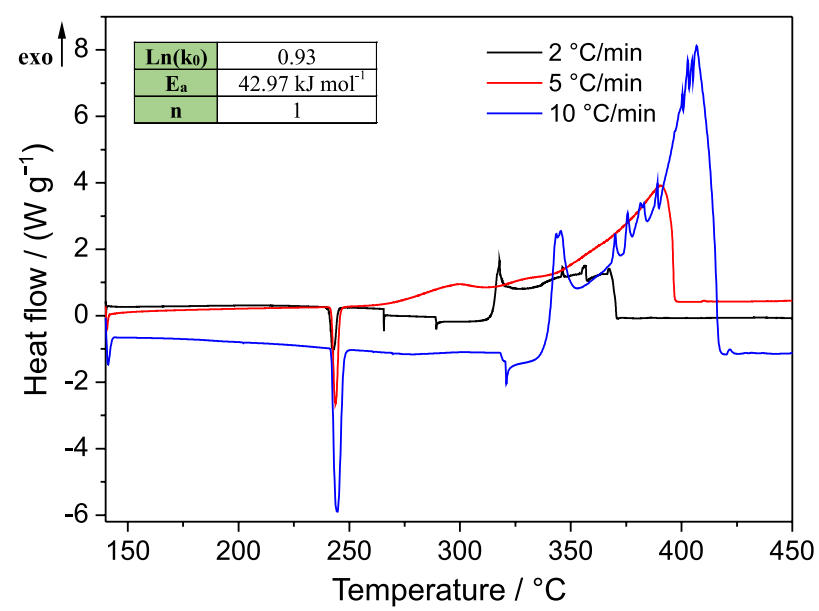

Figure 4. DSC curves of AP with compound 3 at different heating rates.

Table 2. The activation energy $\left(E_{a}\right)$ of the HTD step

\begin{tabular}{lccc}
\hline Compound & Mass / wt. $\%$ & $\mathrm{HTD}$ of $\mathrm{AP} /{ }^{\circ} \mathrm{C}$ & $\mathrm{E}_{\mathrm{a}} /\left(\mathrm{kJ} \mathrm{mol}^{-1}\right)$ \\
\hline $\mathrm{AP}$ & & 415 & 245.8 \\
$\mathbf{1}$ & 5 & 371 & 138.3 \\
$\mathbf{2}$ & 5 & 412 & 131.9 \\
$\mathbf{3}$ & 5 & 347 & 42.9 \\
\hline
\end{tabular}

HTD: high-temperature decomposition; AP: ammonium perchlorate $\left(\mathrm{NH}_{4} \mathrm{ClO}_{4}\right)$.

\section{Conclusions}

The new ruthenocene homobimetallic compound $\mathbf{3}$ was synthesized and isolated in a moderate yield (50\%). This complex was air- and thermally stable in the solid-state, besides being characterized through ${ }^{1} \mathrm{H}$ and ${ }^{13} \mathrm{C}$ NMR spectroscopies and elemental analysis.

The catalytic evaluation results obtained by the DSC technique confirmed that the ruthenocene bimetallic compounds showed catalytic effects on the thermal degradation of ammonium perchlorate. Furthermore, complex $\mathbf{3}$ presented a higher catalytic activity than the other compounds, observed as the lowest thermal degradation temperature $\left(347{ }^{\circ} \mathrm{C}\right)$ and highest energy release $\left(2048 \mathrm{~J} \mathrm{~g}^{-1}\right)$.

Although the effect of the BR catalyst candidates cannot only be focused on the influence on the thermal degradation of AP, the results corroborate that the ruthenocene compounds could have potential uses as BR catalysts for the solid rocket motor. 


\section{Supplementary Information}

Supplementary data (NMR and DSC curves to different wt.\% for all compounds described in this article) are available free of charge at http://jbcs.sbq.org.br as PDF file.

\section{Acknowledgments}

We gratefully acknowledge the financial support from FONDECYT (grant $1210827 \mathrm{C} \mathrm{M-V}$ ) and Project Anillo ACT 192175. We are also grateful to the Scheduled Tribes Welfare Department, Government of Karnataka, India, for a student fellowship (Y.D.) to pursue a research stay at the Pontificia Universidad Católica de Chile and Laboratory of Energy Materials from Institute of Research and Control (IDIC) of the Chilean Army. Furthermore, the authors are grateful to Prof Juan Manuel Manriquez and Prof Ivonne Chavez for their advice.

\section{Author Contributions}

Yuvaraja Dibdalli was responsible for the synthesis of the ruthenium complexes; José Gaete for the characterization of the ruthenium complexes; Claudio Osorio-Gutierrez for the synthesis of the ruthenium complexes; Juan Luis Arroyo for carrying out the experiments of ruthenium compounds and ammonium perchlorate in the differential scanning calorimeter (DSC); Ángel Norambuena for the discussion of the catalytic effects of the ruthenium; Mungalimane K. Amshumali for writing original draft, review, and editing; Gabriel Abarca for the investigation, writing original draft, review, and editing; Cesar Morales-Verdejo for conceptualization, investigation, project administration, supervision, writing original draft, review, and editing.

\section{References}

1. Gromov, A. A.; Pang, W.; Deluca, L. T.; Cummings, A. S. In Innovative Energetic Materials: Properties, Combustion Performance and Application; Pang, W.; DeLuca, L. T.; Gromov, A. A.; Cummings, A. S., eds.; Springer: Singapore, 2020.

2. Joshi, S. S.; Patil, P. R.; Krishnamurthy, V. N.; Def. Sci. J. 2008, 58,721 .

3. Aijun, H.; Juanjuan, L.; Mingquan, Y.; Yan, L.; Xinhua, P.; Chin. J. Chem. Eng. 2011, 19, 1047.

4. Juibari, N. M.; Tarighi, S.; J. Therm. Anal. Calorim. 2018, 133, 1317.

5. Hosseini, S. G.; Gholami, S.; Mahyari, M.; New J. Chem. 2018, 42, 5889.

6. Melo, J. P.; Ríos, P. L.; Povea, P.; Morales-Verdejo, C.; Camarada, M. B.; ACS Omega 2018, 3, 7278.

7. Ríos, P. L.; Povea, P.; Cerda-Cavieres, C.; Arroyo, J. L.;
Morales-Verdejo, C.; Abarca, G.; Camarada, M. B.; RSC Adv 2019, 9, 8480 .

8. Abarca, G.; Paulina, L. R.; Povea, P.; Cerda-cavieres, C.; Morales-Verdejo, C.; Arroyo, J. L.; Camarada, M. B.; RSC Adv. 2020, 10, 23165.

9. Yang, Q.; Chen, S.; Xie, G.; Gao, S.; J. Hazard. Mater. 2011, 197, 199.

10. Liu, J.; Qiu, H.; Han, J.; Yang, L.; Propellants, Explos., Pyrotech. 2019, 2, 816.

11. Escobar, M. A.; Morales-verdejo, C.; Arroyo, L.; Dreyse, P.; González, I.; Brito, I.; Macleod-carey, D.; Cabrera, A. R.; Eur. J. Inorg. Chem. 2021, 1632.

12. Usman, M.; Wang, L.; Yu, H.; Haq, F.; Haroon, M.; Summe Ullah, R.; Khan, A.; Fahad, S.; Nazir, A.; Elshaarani, T.; J. Organomet. Chem. 2018, 872, 40.

13. Usman, M.; Yu, H.; Wang, L.; Zhizhko, P. A.; Lemenovskiy, D. A.; Zarubin, D. N.; Khan, A.; Naveed, K.; J. Organomet. Chem. 2020, 920, 121336.

14. Usman, M.; Wang, L.; Yu, H.; Haq, F.; Liang, R.; Ullah, R. S.; Khan, A.; Nazir, A.; Elshaarani, T.; Naveed, K.-u.-R.; Inorg. Chim. Acta 2019, 495, 118958.

15. Amin, B. U.; Yu, H.; Wang, L.; Nazir, A.; Fahad, S.; Haq, F.; Mahmood, S.; Liang, R.; Uddin, A.; Lin, T.; J. Organomet. Chem. 2020, 921, 121368.

16. Povea, P.; Arroyo, J. L.; Carreño, G.; Norambuena, Á.; Rios, P. L.; Camarada, M. B.; Chavez, I.; Manriquez, J. M.; MoralesVerdejo, C.; Thermochim. Acta 2018, 666, 181.

17. Arroyo, J. L.; Povea, P.; Faúndez, R.; Camarada, M. B.; CerdaCavieres, C.; Abarca, G.; Manriquez, J. M.; Morales-Verdejo, C.; J. Organomet. Chem. 2020, 905, 121020.

18. Gao, J.; Wang, L.; Yu, H.; Xiao, A.; Ding, W.; Propellants, Explos., Pyrotech. 2011, 36, 404.

19. Liu, X.; Zhang, W.; Zhang, G.; Gao, Z.; New J. Chem. 2015, $39,155$.

20. Morales-Verdejo, C.; Camarada, M. B.; Arroyo, J. L.; Povea, P.; Carreño, G.; Manriquez, J. M.; J. Therm. Anal. Calorim. 2018, 131,353

21. Liu, X.; Zhao, D.; Bi, F.; Fan, X.; Zhao, F.; Zhang, G.; Zhang, W.; Gao, Z.; J. Organomet. Chem. 2014, 762, 1.

22. Agrawal, J. P.; High Energy Materials: Explosives, Propellants and Pyrotechnics; Wiley-VCH: Weinheim, Germany, 2010.

23. Arroyo, J. L.; Norambuena, A.; Reyes, H.; Valdebenito, C.; Abarca, G.; Carey, D. M.; Morales-verdejo, C.; Inorg. Chem. 2021, 60, 1436.

24. Hayashi, F.; Toda, Y.; Kanie, Y.; Kitano, M.; Inoue, Y.; Yokoyama, T.; Hara, M.; Hosono, H.; Chem. Sci. 2013, 4, 3124.

25. Wang, Z.; Cai, Z.; Wei, Z.; ACS Sustainable Chem. Eng. 2019, 7, 8226.

26. Manriquez, J. M.; Ward, M. D.; Reiff, W. M.; Calabrese, J. C.; Jones, N. L.; Carroll, P. J.; Bunel, E. E.; Javg, J. S. M.; J. Am. Chem. Soc. 1995, 117, 6182. 
27. Mac-Leod Carey, D.; Morales-Verdejo, C.; Muñoz-Castro, A.; Burgos, F.; Abril, D.; Adams, C.; Molins, E.; Cador, O.; Chávez, I.; Manríquez, J. M.; Arratia-Pérez, R.; Saillard, J. Y.; Polyhedron 2010, 29, 1137.

28. Morales-Verdejo, C.; Martínez-Díaz, I.; Adams, C.; Araneda, J. F.; Oehninger, L.; Mac-Leod Carey, D.; Muñoz-Castro, A.; Arratia-Pérez, R.; Chávez, I.; Manríquez, J. M.; Polyhedron 2014, 69, 15.

29. Aguirre-Etcheverry, P.; O'Hare, D.; Chem. Rev. 2010, 110, 4839.

30. Morales-Verdejo, C. A.; Zarate, X.; Schott, E.; Correa, S.; Martinez-Díaz, I.; RSC Adv. 2015, 5, 25594.

31. Chai, C. L. L.; Armarego, W. L. F.; Purification of Laboratory Chemicals, $5^{\text {th }}$ ed.; Butterworth-Heinemann: Oxford, 2003.

32. ASTM E698-11: Standard Test Method for Arrhenius Kinetic Constants for Thermally Unstable Materials Using Differential Scanning Calorimetry and the Flynn/Wall/Ozawa Method, Philadelphia, 2011.
33. Fagan, P. J.; Mahoney, W. S.; Calabrese, J. C.; Williams, I. D.; Organometallics 1990, 9, 1843.

34. Dahrouch, M. R.; Jara, P.; Mendez, L.; Portilla, Y.; Abril, D.; Alfonso, G.; Chavez, I.; Manriquez, J. M.; Rivie, M.; Rivie, P.; Castel, A.; Rouzaud, J.; Organometallics 2001, 20, 5591.

35. Faúndez, R.; Castillo, F.; Preite, M.; Schott, E.; Zarate, X.; Manriquez, J. M.; Molins, E.; Morales-Verdejo, C.; Chávez, I.; Synthesis 2019, 51, 441.

36. Ceccon, A.; Bisello, A.; Crociani, L.; Gambaro, A.; Ganis, P.; Manoli, F.; Santi, S.; Venzo, A.; J. Organomet. Chem. 2000, 600, 94.

37. Cheng, Z.; Zhang, G.; Fan, X.; Bi, F.; Zhao, F.; Zhang, W.; Gao, Z.; Inorg. Chim. Acta 2014, 421, 191.

Submitted: July 16, 2021

Published online: December 13, 2021 